\title{
Evaluation of Colonoscopy Preparation Using Sodium Phosphate at Different Points in time - a Prospective,Randomized, Endoscopist-Blinded Study
}

\author{
Tao Wei Ke ${ }^{1}$, Yung Feng Huang ${ }^{3}$, William Tzu Liang Chen ${ }^{1}$, Hong Chang Chen ${ }^{1}$, Jau Jie You ${ }^{2}$ and Yang Yuan \\ Chen*3
}

${ }^{1}$ Department of Colorectal Surgery, China Medical University Hospital, Taiwan

${ }^{2}$ Department of Colorectal Surgery, Changhua Christian Hospital, Taiwan

${ }^{3}$ Department of gastroenterology, Changhua Christian Hospital and Yuan-Lin branch, Changhua, Taiwan

Received: April 24, 2018; Published: May 04, 2018

*Corresponding author: Yang Yuan Chen, Department of gastroenterology, Changhua Christian Hospital, Taiwan

\section{Abstract}

Aim: To compare the quality of colonoscopy preparation in patients taking sodium phosphate solution for bowel cleansing at two different time points.

Patients and Methods: One hundred and thirty-three patients were randomized to receive sodium phosphate solution (Fleet $($ )), either in the preceding evening or in the same morning of the colonoscopy. The endpoints of this study include colonic cleansing, determining tolerance and acceptability via a self-administered questionnaire, and assessment of the safety profile of the cleansing agent.

Results: The morning group provided superior results in the overall assessment. $90.8 \%$ of the morning group gave an overall assessment rating of "excellent" or "good" compared to $56.9 \%$ of the evening group $(\mathrm{P}<0.001)$. Generally, the morning group showed better results in stool amount, stool consistency, and bowel wall visualization. Higher rates of abdominal bloating and insomnia were seen in the evening group (53.9\% vs $32.3 \%, \mathrm{P}=0.021 ; 23.1 \%$ vs $7.7 \%, \mathrm{P}=0.027$ ). The morning group had significant increases in serum sodium and phosphate level as well as decrease in serum calcium level on the day following the colonoscopy without any clinical sequelae. Patient acceptability, vital signs, and body weights were comparable for both groups. $78.5 \%$ in the evening group and $81.5 \%$ in the morning group were willing to use the same preparation in the future. Preparation completion rates were high with no significant difference between the two groups $(95.4 \%$ subjects in the evening group completed the preparation and $89.2 \%$ in the morning group, $\mathrm{P}=0.416$ ).

Conclusion: Taking the sodium phosphate solution on the same day of the colonoscopy produced far superior results with consistent cleanliness throughout the colon. Patients were safety and had the benefit of not having to endure some of the overnight discomforts.

\section{Introduction}

Quality bowel preparation with adequate visualization of the colonic mucosa is essential to the success of a colonoscopic examination. Inadequate bowel preparation may lead to an inability to identify lesions [1]. Methods of mechanical bowel preparation have changed widely over the years. Historically, castor oil, anthroquinolones (such as senna), diphenylmethanes (such as bisacodyl or phenolphthalein), and salts (such as sodium picosulfate and magnesium citrate) were used, in combination with a low residue diet. However, bowel cleansing with these agents were usually not sufficient. New mechanical bowel preparation such as Polyethylene glycol has been widely used by colorectal surgeons since its introduction in 1980, and it provided a better quality preparation $[1,2]$. Yet, Fleet $₫$ solution, an osmotic laxative, has also been a popular longstanding alternative since its approval by the U.S. in 1992 and acquisition of a marketing license in Taiwan during July 2003. It provides effective bowel cleansing, while reducing the amount of solution required being ingested [2-7]. Recent studies showed that the time interval between completion of the bowel preparation and start of the colonoscopy predicts the quality of bowel preparation [8,9]. Therefore, the purpose of this investigation was to compare the efficacy, safety, and acceptability of taking one dose of sodium phosphate solution in the early morning of the examination versus taking the dose in the preceding evening of the examination day, in hopes of promoting patient compliance.

\section{Patients and Methods}

From July 2013 to January 2016, one hundred and thirty-three consecutive patients who underwent elective colonoscopy, provided written informed consent, and met the inclusion/exclusion criteria 
were randomized into two treatment groups. One group was assigned to take one $90 \mathrm{ml}$ sodium phosphate solution (Fleet ${ }^{\circledR}$ ) for bowel preparation, diluted with a cold clear liquid or water, at 6:00-7:00PM in the evening before the day of the colonoscopy (PM) while the other took $90 \mathrm{ml}$ at 6:00-7:00AM in the same morning of the colonoscopy (AM). The elective colonoscopy was performed at 11:00-12:00AM.This study (No. C04C04) was approved by both the Health Department of Taiwan and the Institutional Review Board of Changhua Christian Hospital, Taiwan. Exclusion criteria included symptomatic congestive heart failure (CHF), myocardial infarction, serum creatinine levels greater than $1.5 \mathrm{mg} / \mathrm{dL}$, abnormal liver function defined as glutamic-oxaloacetic transaminase (GOT) and glutamic-pyruvic transaminase (GPT) each greater than 120U/L, ascites, electrolyte abnormalities, gastrointestinal obstructions, gastric retention, bowel perforations, toxic colitis, toxic megacolon, ileus, known hypomotility syndrome, uncontrolled hypertension, unstable angina pectoris, clinical evidence of dehydration, or severe chronic constipation.

Further exclusion criteria included women who were pregnant or breastfeeding, those using investigational drugs, those unable to communicate to the study personnel or unable to understand bowel preparation instructions, inability to take oral hydration adequately, or patients with known allergies to the medications used in this study. Demographic characteristics such as age, gender, prior bowel preparation experience, and reasons for colonoscopy were obtained for all patients. Laboratory assessment including levels of sodium $(\mathrm{Na})$, potassium $(\mathrm{K})$, chloride $(\mathrm{Cl})$, calcium $(\mathrm{Ca})$, and phosphate $(\mathrm{P})$ were collected at baseline (defined as the day of screening and consent, within 30 days prior to the colonoscopy) and on the day following the colonoscopy. In addition to this, pregnancy tests were performed on female patients and electrocardiograms were performed on patients who did not have a record of one in the last 6 months during the initial screening visit. Body weight and vital signs (pulse rate, blood pressure, and temperature) were obtained at baseline on the day of the colonoscopy and on the following day. Blood pressure and pulse rate were measured after patients were kept resting in supine position 5 minutes and again in standing position after 1 minute.

Aself-administered questionnaire was completed by the patients to assess the tolerance and acceptability of the bowel preparation. The taste of the oral solutions was graded as very poor, poor, fair, good, and excellent. The ease of taking, swallowing, convenience of the preparation, and the entire process were rated on a scale of very difficult, difficult, tolerable, easy, and very easy. Additional topics covered on the questionnaire included occurrence and severity of certain adverse events commonly associated with bowel preparation, the percentage of solution ingested, and willingness to repeat the same preparation in the future. Patients were instructed to complete and return the questionnaire prior to undergoing the colonoscopy. A single surgeon blinded to the patient's study group performed all of the colonoscopies. Data records included the time taken to reach the cecum, the insertion and removal time of the scope, the volume of fluid irrigated and suctioned, and the segment of colon reached.Colonic cleansing was evaluated based on the amount of stool (none, small, moderate, or large), consistency of stool (none, clear lavage, liquid stool, particulate stool, semi-solid stool, and solid stool), and the estimated percentage of the bowel wall visualized $(<49 \%, 50-74 \%, 75-89 \%$, and $>90 \%)$ at various segments of the colon, as well as the overall assessment of the preparation rated by the colonoscopist (small volume of clear liquid, large volume of clear liquid, some semi-solid stool that could be suctioned or washed away, and semi-solid stool that could not be suctioned or washed away).

\section{Statistical Analysis}

A p-value smaller than 0.05 was considered to be statistically significant. Intention-to-treat analysis was used for data interpretation and imputation of missing data was not performed. Fisher's exact test was used to compare the ordinal scores of the global and segmental assessments of bowel cleansing, patient preference, and acceptability between the two groups. The CochranMantel-Haenszel $\chi 2$ test was used to compare these categorical variables between the two groups, controlling for the completion of oral solution. General linear regression analysis was conducted by SAS Proc GLM procedure (SAS v.8.2, SAS Institute Inc., Cary, NC, USA) for the comparison of continuous variables between the two groups, controlling for the completion of oral solution. Deviations from baseline laboratory results and vital signs were summarized and analyzed with t-tests.

\section{Results}

Table 1: Demographic characteristics and prior bowel preparation experience.

\begin{tabular}{|c|c|c|c|c|}
\hline Variables & & $\begin{array}{c}\text { PM n(\%) } \\
(n=67)\end{array}$ & $\begin{array}{c}\text { AM n(\%) } \\
(n=66)\end{array}$ & $P^{1}$ \\
\hline \multicolumn{2}{|c|}{ Gender } & & 0.381 & \\
\hline & Male & $25(37.3)$ & $30(45.5)$ & \\
\hline & Female & $42(62.7)$ & $36(54.5)$ & \\
\hline \multirow[t]{2}{*}{ Age } & & & & 0.178 \\
\hline & Mean \pm SD & $52.1 \pm 12.6$ & $55.2 \pm 13.7$ & \\
\hline \multirow[t]{4}{*}{ Frame Size } & & & 0.723 & \\
\hline & Small & $3(4.5)$ & $1(1.5)$ & \\
\hline & Medium & $60(89.5)$ & $61(92.4)$ & \\
\hline & Large & $4(6.0)$ & $4(6.1)$ & \\
\hline \multirow[t]{2}{*}{$\begin{array}{l}\text { Previous Bowel } \\
\text { Preparation }\end{array}$} & & & 0.432 & \\
\hline & Yes & $20(29.9)$ & $15(22.7)$ & \\
\hline \multirow[t]{6}{*}{$\begin{array}{c}\text { Overall Tolerance } \\
\text { to Preparation }\end{array}$} & & & 0.516 & \\
\hline & Poor & $0(0.0)$ & $1(6.7)$ & \\
\hline & Fair & $9(45.0)$ & $7(46.7)$ & \\
\hline & Good & $10(50.0)$ & $5(33.3)$ & \\
\hline & Very Good & $0(0.0)$ & $0(0.0)$ & \\
\hline & Excellent & $1(5.0)$ & $2(13.3)$ & \\
\hline
\end{tabular}

${ }^{1} \mathrm{P}$-value from Fisher's exact test for categorical data and ANOVA for continuous data. 
Of 140 patients with consecutive patients who underwent elective colonoscopy, and during the study period, 6 patients were excluded ( 1 had symptomatic congestive heart failure, 2 were abnormal renal function, 3 were abnormal liver function.). They were randomized into two treatment groups. One group (68 patients) was assigned to take sodium phosphate solution (Fleet $囚$ ) for bowel preparationat 6:00-7:00PM in the evening before the day of the colonoscopy (PM) while the other (66 patients) took fleet at 6:00-7:00AM in the same morning of the colonoscopy (AM). The elective colonoscopy was performed at 11:00-12:00AM. Only one patient refused blood laboratory test during follow-up. A flow diagram for the study is provided in Figure
1. The demographic characteristics and prior bowel preparation experience are presented in Table 1. No significant differences in any of these variables were observed between the two groups. The primary indications for colonoscopy were change in bowel habits (46/133; 34.6\%), history of polyps $(24 / 133 ; 18.0 \%)$, family history of cancer $(20 / 133 ; 15.0 \%)$, bleeding $(15 / 133 ; 11.3 \%)$, and cancer surveillance $(13 / 133 ; 9.8 \%)$. Three patients did not complete the study due to personal reasons and completion rate of $97.0 \%$ in PM (65/67) vs. $98.5 \%$ in AM (65/66). Comparably high solution completion rates were shown no significant differences for both the groups of patients (95.4\% in PM vs. $89.2 \%$ in AM).

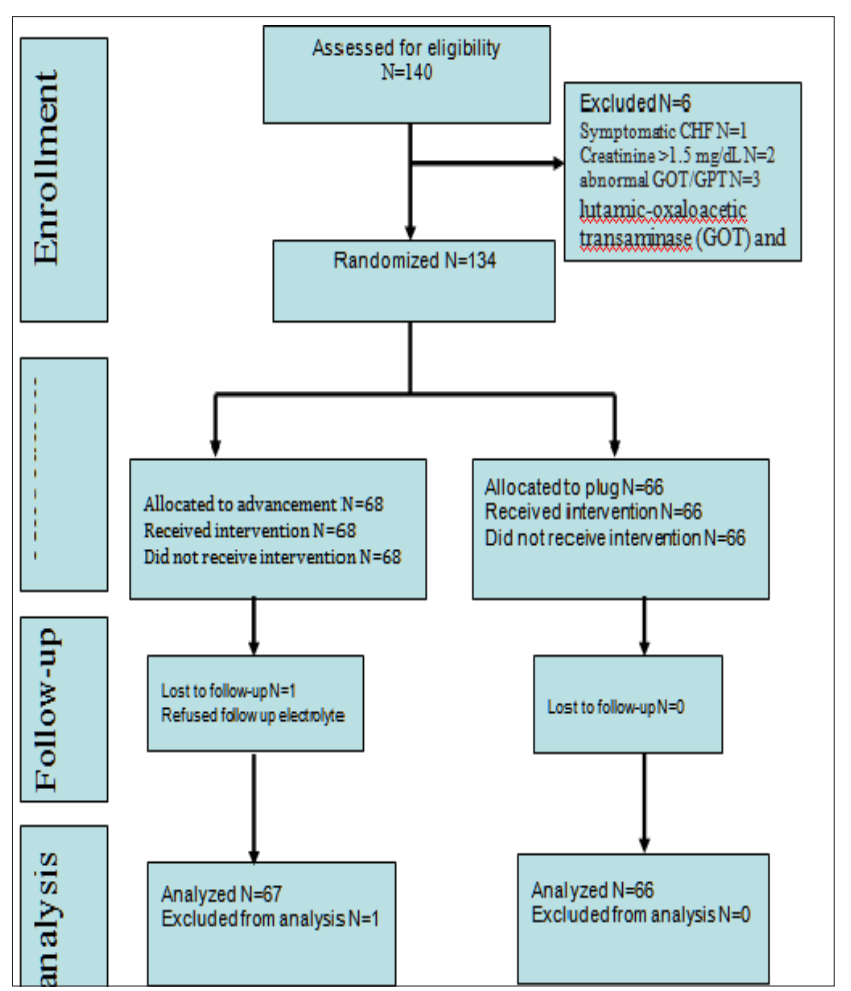

Figure 1.

\section{Assessment of Bowel Cleaning}

Table 2: Overall assessment of preparation.

\begin{tabular}{|c|c|c|c|c|c|c|c|}
\hline Group & Excellent N(\%) & Good N(\%) & Fair N(\%) & Poor N(\%) & $\mathbf{P}$ & $\begin{array}{c}\text { Good/ } \\
\text { Excellent N(\%) }\end{array}$ & $\mathbf{P}$ \\
\hline \multicolumn{8}{|l|}{ Overall } \\
\hline PM & $21(32.3)$ & $16(24.6)$ & $20(30.8)$ & $8(12.3)$ & $<0.001^{1}$ & $37(56.9)$ & $<0.001^{1}$ \\
\hline $\mathrm{AM}$ & $44(68.0)$ & $15(23.1)$ & $5(7.7)$ & $1(1.5)$ & & $59(90.8)$ & \\
\hline Complete & & & & & $<0.001^{2}$ & & $<0.001^{2}$ \\
\hline $\mathrm{PM}$ & $19(30.7)$ & $15(24.2)$ & $20(32.3)$ & $8(12.9)$ & & $34(54.8)$ & \\
\hline $\mathrm{AM}$ & $41(71.0)$ & $12(20.7)$ & $4(6.9)$ & $1(1.7)$ & & $53(91.4)$ & \\
\hline \multicolumn{8}{|l|}{ Incomplete } \\
\hline PM & $2(66.7)$ & $1(33.3)$ & $0(0.0)$ & $0(0.0)$ & & $3(100)$ & \\
\hline $\mathrm{AM}$ & $3(42.3)$ & $3(42.9)$ & $1(14.3)$ & $0(0.0)$ & & 6(85.7) & \\
\hline
\end{tabular}

${ }^{1}$ P-value from Cochran-Mantel-Haenszel Chi-square test;

${ }^{2} \mathrm{P}$-value from Fisher's exact test 
The morning group had double the number of overall "excellent" ratings scored by the colonoscopist (68.0\% in AM vs. $32.3 \%$ in PM). Even after combining "excellent" and "good" ratings, the morning group still exhibited superior assessment ratings over the evening group ( $\mathrm{P}<0.001$ ) (Table 2). Overall assessment of the preparation was further broken down into stool amount, stool consistency, and percentage of colonic wall visualized. Comparison of these subgroups revealed that the morning group outcomes were far superior to those of the evening group in many aspects. Stool amount of the morning group had consistently "none" or Table 3: Colonic segmental assessment of preparation. "small" (vs. "moderate" or "large") from the rectum up to cecum, values ranging from $87.5 \%$ to $92.3 \%$. The same comparison of stool amount in the evening group showed a drop from $95.3 \%$ in the rectum to $66.7 \%$ in the cecum. Stool consistency along various segments also differed significantly between the two groups. The morning group maintained a stool consistency of none or clear lavage over $80 \%$ throughout the colon while the evening group dropped from over $80 \%$ in the rectum to $40 \%$ in the cecum. Better colonic wall visualization was also seen in the morning group (Table 3).

\begin{tabular}{|c|c|c|c|c|c|c|c|c|c|}
\hline & \multicolumn{3}{|c|}{ Stool amount (none/small)N(\%) } & \multicolumn{3}{|c|}{$\begin{array}{c}\text { Stool consistency(none/clear lavage) } \\
\mathrm{N}(\%)\end{array}$} & \multicolumn{3}{|c|}{$\%$ Colonic wallvisualized $(>75 \%) \mathrm{N}(\%)$} \\
\hline & PM & AM & $\mathbf{P}^{1}$ & PM & AM & $\mathbf{P}^{1}$ & PM & AM & $\mathbf{P}^{1}$ \\
\hline Rectum & $61(95.3)$ & $59(90.8)$ & 0.492 & $56(87.5)$ & $62(95.4)$ & 0.127 & $62(96.9)$ & $64(98.5)$ & 0.619 \\
\hline Descending & $58(90.6)$ & $60(92.3)$ & 0.763 & $44(68.8)$ & $57(87.7)$ & 0.011 & $60(93.8)$ & $65(100)$ & 0.058 \\
\hline Transverse & $57(87.7)$ & $57(87.7)$ & 1.000 & $42(64.6)$ & $58(89.2)$ & 0.001 & $61(93.8)$ & 63(96.9) & 0.680 \\
\hline Ascending & $53(84.1)$ & $56(87.5)$ & 0.620 & $37(58.7)$ & $53(82.8)$ & 0.003 & $57(90.5)$ & 63(98.4) & 0.062 \\
\hline Cecum & $42(66.7)$ & $57(89.0)$ & 0.003 & $28(44.4)$ & $53(82.8)$ & $<0.001$ & $50(79.4)$ & $62(96.9)$ & 0.002 \\
\hline
\end{tabular}

${ }^{1} \mathrm{P}$-value from Fisher's exact test

\section{Adverse Events}

A total of 104 patients had adverse events during the study period, most of which were mild. General reports of side effects included nausea, vomiting, abdominal bloating, abdominal pain, Table 4: Occurrence and severity of anticipated adverse events. anal irritation and dizziness (Table 4). Rates of occurrences were comparable between both groups. The evening group had higher occurrences of abdominal bloating (53.9\% in $\mathrm{PM}, 32.3 \%$ in $\mathrm{AM}$; $\mathrm{P}=0.021)$ and insomnia (23.1\% in $\mathrm{PM}, 7.7 \%$ in $\mathrm{AM} ; \mathrm{P}=0.027)$.

\begin{tabular}{|c|c|c|c|c|c|c|c|c|c|}
\hline & \multicolumn{4}{|c|}{ PM } & \multicolumn{4}{|c|}{ AM } & \multirow[t]{2}{*}{ P1 } \\
\hline & Mi & Mo & $S$ & Occ (\%) & Mi & Mo & S & Occ (\%) & \\
\hline Nausea & 26 & 10 & 8 & $44(67.7)$ & 32 & 6 & 6 & $44(67.7)$ & 1.000 \\
\hline Vomiting & 15 & 7 & 9 & $31(47.7)$ & 24 & 8 & 5 & $37(56.9)$ & 0.380 \\
\hline $\begin{array}{l}\text { Abdominal } \\
\text { bloating }\end{array}$ & 24 & 5 & 6 & $35(53.9)$ & 18 & 2 & 1 & $21(32.3)$ & 0.021 \\
\hline $\begin{array}{l}\text { Abdominal } \\
\text { pain }\end{array}$ & 18 & 4 & 1 & $23(35.4)$ & 15 & 2 & 0 & $17(26.2)$ & 0.342 \\
\hline $\begin{array}{c}\text { Anal } \\
\text { Irritation }\end{array}$ & 17 & 2 & 6 & $25(38.5)$ & 22 & 6 & 1 & $29(45.3)$ & 0.478 \\
\hline Dizziness & 17 & 6 & 4 & $27(41.5)$ & 31 & 2 & 2 & $35(53.9)$ & 0.219 \\
\hline Chills & 7 & 1 & 2 & $10(15.4)$ & 6 & 1 & 1 & $8(12.3)$ & 0.800 \\
\hline Hungry Pain & 5 & 3 & 0 & $8(12.3)$ & 9 & 1 & 0 & $10(15.4)$ & 0.800 \\
\hline Headache & 7 & 3 & 2 & $12(18.5)$ & 5 & 2 & 0 & $7(10.8)$ & 0.321 \\
\hline Insomnia & 9 & 4 & 2 & $15(23.1)$ & 3 & 2 & 0 & $5(7.7)$ & 0.027 \\
\hline Any AE & & & & $54(93.1)$ & & & & $50(87.7)$ & 0.361 \\
\hline
\end{tabular}

Mi=Mild; Mo=Moderate; $\mathrm{S}=$ Severe; Occ=Occurrence. ${ }^{1} \mathrm{P}$-value from Fisher's exact test

Serum Electrolyte Changes

Table 5: Electrolytes (Mean \pm SD).

\begin{tabular}{|c|c|c|c|c|c|c|c|}
\hline & \multicolumn{3}{|c|}{ PM } & \multicolumn{3}{|c|}{$\mathbf{A M}$} & \multirow[b]{2}{*}{ P1 } \\
\hline & Baseline & Follow-up & Change & Baseline & Follow-up & Change & \\
\hline $\mathrm{Na}(\mathrm{meq} / \mathrm{L})$ & $141.5 \pm 2.4$ & $143.4 \pm 3.0$ & $1.9 \pm 3.1$ & $140.9 \pm 2.7$ & $145.0 \pm 4.0$ & $4.0 \pm 4.1$ & 0.001 \\
\hline $\mathrm{K}(\mathrm{meq} / \mathrm{L})$ & $4.2 \pm 0.3$ & $3.6 \pm 0.3$ & $-0.6 \pm 0.4$ & $4.2 \pm 0.5$ & $3.8 \pm 0.4$ & $-0.5 \pm 0.5$ & 0.222 \\
\hline $\mathrm{Cl}(\mathrm{meq} / \mathrm{L})$ & $103.9 \pm 2.5$ & $106.6 \pm 2.9$ & $2.7 \pm 3.2$ & $103.3 \pm 3.1$ & $107.0 \pm 3.9$ & $3.7 \pm 4.0$ & 0.130 \\
\hline
\end{tabular}




\begin{tabular}{|c|c|c|c|c|c|c|c|}
\hline $\mathrm{Ca}(\mathrm{mg} / \mathrm{dL})$ & $9.2 \pm 0.4$ & $8.5 \pm 0.5$ & $-0.7 \pm 0.6$ & $9.1 \pm 0.4$ & $8.7 \pm 0.5$ & $-0.4 \pm 0.6$ & 0.005 \\
\hline $\mathrm{P}(\mathrm{mg} / \mathrm{dL})$ & $3.3 \pm 0.6$ & $4.3 \pm 1.2$ & $1.0 \pm 1.3$ & $3.3 \pm 0.5$ & $6.8 \pm 2.4$ & $3.6 \pm 2.5$ & $<0.001$ \\
\hline
\end{tabular}

${ }^{1} \mathrm{P}$-value from t-test comparing the changes from baseline at follow-up

Any changes from baseline electrolyte levels detected during the follow-up visit were recorded. Significant increases in $\mathrm{Na}$ and $\mathrm{P}$ were seen in the morning group compared to that of the evening group ( $\mathrm{P}=0.001$ and $\mathrm{P}<0.001$, respectively). Changes in $\mathrm{K}$ and $\mathrm{Cl}$ were similar for both groups (Table 5). Regardless of the observed changes, no patient reported any discomfort related to these laboratory test results.

\section{Patient Acceptability and Preference}

Because both groups took the same preparation, the only observable differences were in various aspects of intake. Patient acceptability and preference were all comparable between the two groups (Table 6). Almost half of the patients (46.2\%) graded the

Table 6:: Patient acceptability.

\begin{tabular}{|c|c|c|c|c|c|c|}
\hline & $\begin{array}{c}\text { Very Poor/ } \\
\text { Difficult (\%) }\end{array}$ & $\begin{array}{c}\text { Poor/ Difficult } \\
\text { (\%) }\end{array}$ & Fair (\%) & Good/ Easy (\%) & $\begin{array}{c}\text { Very Good/ Easy } \\
(\%)\end{array}$ & P-value ${ }^{1}$ \\
\hline Taste & & & & & & 0.793 \\
\hline $\mathrm{PM}$ & $12(18.5)$ & $14(21.5)$ & $30(46.2)$ & $7(10.8)$ & $2(3.1)$ & \\
\hline AM & $9(13.8)$ & $11(16.9)$ & $36(55.4)$ & $8(12.3)$ & $1(1.5)$ & \\
\hline Ease of intake & & & & & & 0.613 \\
\hline PM & $3(4.6)$ & $6(9.2)$ & $31(47.7)$ & $21(32.3)$ & $4(6.2)$ & \\
\hline $\mathrm{AM}$ & $0(0.0)$ & $6(9.2)$ & $34(52.3)$ & $21(32.3)$ & $4(6.2)$ & \\
\hline Ease of swallow & & & & & & 1.000 \\
\hline PM & $2(3.1)$ & $4(6.2)$ & $32(49.2)$ & $23(35.4)$ & $4(6.2)$ & \\
\hline $\mathrm{AM}$ & $1(1.5)$ & $5(7.7)$ & $31(47.7)$ & $24(36.9)$ & $4(6.2)$ & \\
\hline $\begin{array}{l}\text { Convenience of } \\
\text { intake }\end{array}$ & & & & & & 0.874 \\
\hline PM & $0(0.0)$ & $3(4.6)$ & $26(40.0)$ & $30(46.2)$ & $6(9.2)$ & \\
\hline $\mathrm{AM}$ & $0(0.0)$ & $2(3.1)$ & $30(46.2)$ & $28(43.1)$ & $5(7.7)$ & \\
\hline Ease of preparation & & & & & & 0.693 \\
\hline $\mathrm{PM}$ & $1(1.5)$ & $5(7.7)$ & $31(47.7)$ & $24(36.9)$ & $4(6.2)$ & \\
\hline $\mathrm{AM}$ & $0(0.0)$ & $3(4.6)$ & $32(49.2)$ & $28(43.1)$ & $2(3.1)$ & \\
\hline
\end{tabular}

\section{Discussion}

Patient compliance with bowel preparation is crucial for an accurate colonoscopy screening which may aid in the early diagnosis of colonic neoplasia. Methods of mechanical bowel preparation have changed widely over the years. Fleet ${ }^{\circledR}$ Phospho-soda ${ }^{\circledR}$ solutionand polyethylene glycol are bowel preparation agents extensively utilized to "cleanse" the colon prior to colonoscopy, radiographic procedures, and surgery. Yet, most of the randomized trials conducted in the United States, Canada, and Australia have suggested that patients taking sodium phosphate for colonoscopies have a higher percentage of completing the preparation compared to those taking polyethylene glycol [10-13]. Sodium phosphate was also reported to be equally or more effective and equally or better tolerated than polyethylene glycol [2,3,10-14]. Further investigation in various methods of administering sodium phosphate, associated

\section{Hemodynamic Profile and Body Weight}

The magnitude of changes in standing and supine blood pressure was similar for both groups. Decreased blood pressure observed during follow-up visits showed no clinical significance, such as syncopal episodes or postural dizziness. Body temperature and weight showed no noticeable deviations from the baseline.

taste of the preparation as fair while slightly under $15 \%$ of patients rated the taste as good or very good. Furthermore, around $90 \%$ of patients rated the ease of intake and swallowing, convenience, and preparation as very easy to fair. Lastly, around $80 \%$ of subjects answered that they would be willing to use the same preparation if another colonoscopy was to be performed in the future. cleansing efficacy, and resulting patient response may lead to better colonoscopic outcomes.

The primary mode of action for Fleet $®$ Phospho-soda $₫$ solution is thought to be through osmotic effect of phosphate, which draws large amounts of water into the bowel, creating a flushing action resulting in a laxative effect which starts within 30 minutes and lasting, on average, two to three hours $[3,15,16]$. The recommended way of administering NaP solutions is to take $45 \mathrm{ml}$ each time with 12 hours internal. However, our study demonstrated that the morning group, which took $90 \mathrm{ml}$ at 6:00-7:00AM on the same morning of the colonoscopy, provided better results in bowel cleansing $(90.8 \%$ in $\mathrm{AM}$ vs. $56.9 \%$ in $\mathrm{PM}$; $\mathrm{P}<0.001$ ) and rate of solution completion (95.4\% in PM vs. 89.2\% in AM). These results suggest an advantage in efficacy when administering sodium phosphate in the morning of the colonoscopy. Another aspect to consider in a good bowel 
preparation agent is safety. Like all other bowel cleansing methods, sodium phosphate may cause diarrhea, trouble drinking liquids, loss of sleep, abdominal fullness or bloating, abdominal cramps or pain, nausea, vomiting, anal irritation, and weakness.All of the minor adverse effects reported in this study were resolved shortly after the examination and regular meals were being ingested. Increased rates of insomnia observed in the evening group could be explained by the discomfort patients had to endure overnight, which also affected the quality of their sleep.

An Australian study found that patients taking sodium phosphate had a slightly higher incidence of minor side effects [17], which was in contrast to most of the other trials performed. Other studies reported asymptomatic hyperphosphatasemia observed in all patients taking sodium phosphate $[2,13,18]$, while some reported a significant decrease in serum calcium level after being administered both agents, with no adverse clinical sequelae10. Some studies suggested that sodium phosphate preparation in patients with normal renal function was not associated with renal injury [19]. In elderly patients, it was reported to be effective and well tolerated with a low adverse effect rate and it was also safe and tolerable in diabetic patients [20]. In our study, the morning group did exhibit a significant increase in $\mathrm{Na}$ and $\mathrm{P}$ compared to that of the evening group ( $\mathrm{P}=0.001$ and $\mathrm{P}<0.001$, respectively).

This transient hyperphosphatasemia may limit the use of sodium phosphate in patients with impaired renal function. Patient acceptability and preference are also key to choosing the right bowel preparation agent. A trial conducted in Singapore, Asia showed consistent results of both agents being equally tolerated by patients, but sodium phosphate scored higher in overall assessments and thus labeled as a better bowel preparation agent [21-22]. All these trials agreed that more patients (ranging from 65-89\%) preferred sodium phosphate and stated that they would repeat the same preparation, compared to $19-73 \%$ for polyethylene glycol [10$12,14,17]$. Our present study agreed with these results, indicating that around $80 \%$ of subjects had no qualms about using the same preparation should future colonoscopies be performed. Lastly, taking into consideration the number of repeated procedures due to inadequate preparation, sodium phosphate was also considered more cost-effective than polyethylene glycol $[13,14]$.

\section{Conclusion}

In conclusion, this study demonstrated that administration of the preparation formula, sodium phosphate solution (Fleet $\AA$ Phospho-soda () , on the same day of the colonoscopy produced better results and consistent cleanliness throughout the colon. Both groups exhibited similar safety profiles, though the morning group experienced less overnight discomfort. Patient acceptability and preference were all comparable between the two groups.

\section{Acknowledgement}

This work was supported by grant $\mathrm{C} 04 \mathrm{C} 04$ from the Chang-Hua Christian Hospital. We thank Mrs. Kai-Lin Hwang, Department of Public Health, Chung-Shan Medical University for study design and statistical analysis. We especially thank the help of Enterostoma
Therapy nurses of Pei-Jung Chi, Huei-Huei Lin, Department of Colorectal Surgery, Chang-Hua Christian Hospital, Taiwan, for the data collection.

\section{References}

1 Park JS, Sohn CI, Hwang SJ, Choi HS, Park JH, et al. (2007) Quality and effect of single dose versus split dose of polyethylene glycol bowel preparation for early-morning colonoscopy. Endoscopy 39(7): 616-669.

2 Zmora O, Pikarsky AJ, Wexner SD. (2001) Bowel Preparation for Colorectal Surgery. Dis Colon Rectum 44(10): 1537-1549.

3 Hwang KL, Chen WT, Hsiao KH, Chen HC, Huang TM, et al. (2005) Prospective randomized comparison of oral sodium phosphate and polyethylene glycol lavage for colonoscopy preparation. World J Gastroenterol 11(47): 7486-7493.

4 Tjandra JJ,Chan M, Tagkalidis PP (2006). Oral sodium phosphate (Fleet) is a superior colonoscopy preparation to Picopre (sodium picosulfatebased preparation). Dis Colon Rectum 49(5): 616-620.

5 Renaut AJ, RanigaS,Frizelle FA, Perry RE, Guilford L.A (2008) A randomized controlled trial comparing the efficacy and acceptability of phospo-soda buffered saline (Fleet) with sodium picosulphate/ magnesium citrate (Picoprep) in the preparation of patients for colonoscopy. Colorectal Dis 10(5): 503-505.

6 Delegge M, Kaplan R (2005) Efficacy of bowel preparation with the use of a prepackaged, low fibre diet with a low sodium, magnesium citrate cathartic vs. a clear liquid diet with a standard sodium phosphate cathartic. Aliment Pharmacol Ther 21(12):1491-1495.

7 Scott SR, Raymond PL, Thompson WO, Galt DJ. (2005) Efficacy and tolerance of sodium phosphates oral solution after diet liberalization. Gastroenterol Nurs 28(2): 133-139.

8 Siddiqui AA, Yang K, Spechler SJ, Cryer B, Davila R, et al. (2009) Duration of the interval between the completion of bowel preparation and the start of colonoscopy predicts bowel-preparation quality. Gastrointest Endosc 69(2): 700-706.

9 Varughese S, Kumar AR, George A, Castro FJ (2010) Morning-Only OneGallon Polyethylene Glycol Improves Bowel Cleansing for Afternoon Colonoscopies: A Randomized Endoscopist-Blinded Prospective Study. Am J Gastroenterol 105(11): 2368-2374.

10 Oliveira L,Wexner SD, Daniel N, De Marta D, Weiss EG, et al. (1997) Mechanical Bowel Preparation for Elective Colorectal Surgery. A Prospective, Randomized, Surgeon-blinded Trial Comparing Sodium Phosphate and Polyethylene Glycol-based Oral Lavage Solutions. Dis Colon Rectum 40(5): 585-591.

11 Golub RW, Kerner BA, Wise WE Jr, Meesig DM, Hartmann RF,et al. (1995) Colonoscopic Bowel Preparations-Which One? A Blinded, Prospective, Randomized Trial. Dis Colon Rectum 38(6): 594-599.

12 Cohen SM, Wexner SD, Binderow SR, Nogueras JJ, Daniel N, et al. (1994) Prospective, Randomized, Endoscopic-blinded Trial Comparing Precolonoscopy Bowel Cleansing Methods. Dis Colon Rectum 37(7): 689-696.

13 Kolts BE, Lyles WE, Achem SR, Burton L, Geller AJ (1993) A comparison of the Effectiveness and Patient Tolerance of Oral Sodium Phosphate,Castor Oil, and Standard Electrolyte Lavage for Colonoscopy or Sigmoidoscopy Preparation. Am J Gastroent 88(8): 1218-1223.

14 Hsu CW, Imperiale TF (1998) Meta-analysis and Cost Comparison of Polyethylene Glycol Lavage Versus Sodium Phosphate for Colonoscopy Preparation. Gastrointest Endosc 48(3): 276-282.

15 Vanner SJ, MacDonald PH, Paterson WG, Prentice RS, Da Costa LR (1990) A Randomized Prospective Trial Comparing Oral Sodium Phosphate with Standard Polyethylene Glycol-Based Lavage Solution (Golytely) in the Preparation of Patients for Colonoscopy. Am J Gastroent 85(4): 422427. 
16 Davis GR, Santa Ana CA, Morawski SG, Fordtran JS (1980) Development of a lavage solution associated with minimal water and electrolyte absorption or secretion. Gastroenterology 78(5): 991-995.

17 Frommer D (1997) Cleansing Ability and Tolerance of Three Bowe Preparations for Colonoscopy. Dis Colon Rectum 40(1): 100-104.

18 Huynh T, Vanner S, Peterson W(1995) Safety Profile of 5-h Oral Sodium Phosphate Regimen for Colonoscopy Cleansing: Lack of Clinically Significant Hypocalcemia or Hypovolemia. Am J Gastroent 90(1): 104 107.

19 Seol DC, Hong SN, Kim JH, Sung IK, Park HS, et al. (2010) Change in renal function after sodium phosphate preparation for screening colonoscopy. World J Gastroenterol 16(16): 2010-2016.

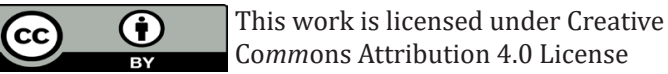

Submission Link: https://biomedres.us/submit-manuscript.php
20 Yakut M, Cinar K, Seven G, Cetınkaya H, Bahar K (2010) The efficacy and safety of colonoscopy preparation with oral sodium phosphate in elderly patients. Turk J Gastroenterol 21(2): 140-145.

21 Ozturk NA, Gokturk HS, Demir M, Unler GK, Gur G (2010 )Efficacy and Safety of Sodium Phosphate for Colon Cleansing in Type 2 Diabetes Mellitus. South Med J 103(11): 1097-1102.

22 Chia YW, Cheng LC, Goh PM, Ngoi SS, Isaac J, et al. (1995) Role of Oral Sodium Phosphate and Its Effectiveness in Large Bowel Preparation for Out-patient Colonoscopy. J R Coll Surg Edinb 40(6): 374-376.

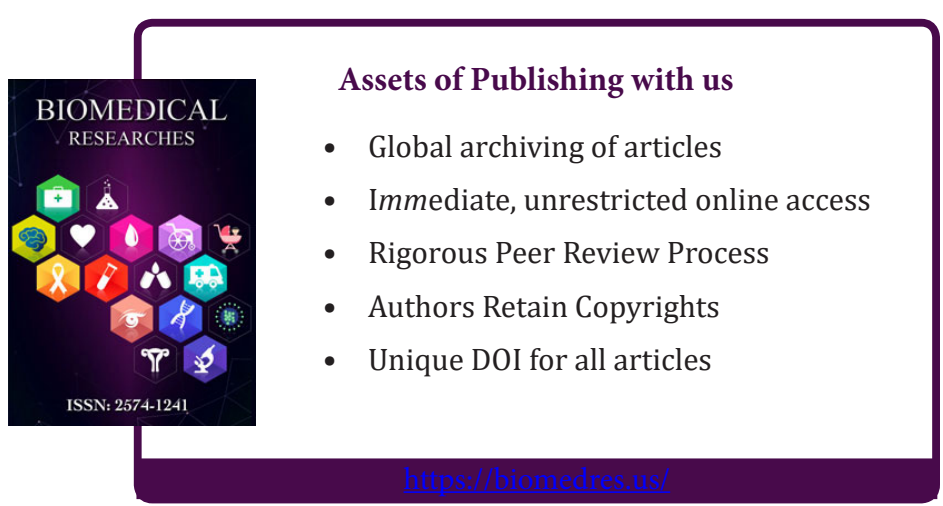

